\title{
Um mergulho no "morro do querosene" e o encontro com os artistas do invisível: reflexões sobre arte, comun(idade), afeto e práxis psicossocial
}

\author{
A dip in the "morro do querosene" and meeting with the artists of the \\ invisible: reflections about art, community, affection and \\ psychosocial praxis
}

http://dx.doi.org/10.5007/2178-4582.2016v50n2p315

Lívia Maria Camilo dos Santos

Bader Burihan Sawaia

Pontifícia Universidade Católica de São Paulo, São Paulo/SP, Brasil

\begin{abstract}
Trata-se de uma reflexão sobre arte e formas de (con)viver, com foco na análise das afetações que manifestações artísticas tradicionais promovem em um bairro. Vigotski é autor de referência, com sua defesa do psicológico como fenômeno sócio-histórico, da positividade dos afetos e da concepção de arte como a linguagem das emoções. As reflexões partem de pesquisa realizada no "Morro do Querosene", situado na cidade mais populosa e de maior poder aquisitivo do Brasil, que possui uma história marcada pela arte e cultura. Elas evidenciam que atividades artísticas, quando realizadas na rua, promovem encontros que favorecem configurações comunitárias, paralelamente à explicitação das contradições e relações de poder que permeiam o cotidiano dos moradores. Os relatos de dois mestres de expressões culturais diferentes, bumba meu boi e capoeira, sugerem que é possível fazer a vida pessoal e urbana por outras vias, oferecendo subsídios à práxis psicossocial potencializadora do agir em comum.
\end{abstract}

Palavras-chave: arte; cultura popular; afeto; (comun)idade; práxis psicossocial.
The present work is a reflection about art, community and affection with focus on the analysis of the affectations that popular culture promotes in a neighborhood. The theoretical benchmark is the Vigotski's psychological understanding as socio-historical phenomenon by retrieving the positivity of emotions and conception of art as a language of emotions. The reflections are based on a survey made at Morro do Querosene, located in the most populous city and greater purchasing power of Brazil, which has a history marked by art and culture. They show that the popular culture when performed on the streets favors holds meetings that favor community settings, alongside the explicitiness the contradictions and power relationships that pervade the daily lives of the residents. The reports of two masters of diferents cultural expressions, bumba meu boi and capoeira, suggest that it is possible to build personal and urban life other means, offering subsidies potentiating psychosocial praxis of acting in common.

Keywords: art; popular culture; affection; community; psychosocial praxis.

\section{Introdução}

O presente artigo é uma reflexão sobre práxis psicossocial em um território, tendo como norte a ideia espinosana do "comum" e como pressuposto da ação a arte na concepção vigotskiana. Baseia-se em uma pesquisa que teve como foco as afetações de um bairro pela mediação de duas expressões artísticas tradicionais: o bumba meu boi e a capoeira. Parte do pressuposto de que as ações desenvolvidas pelas pessoas no cotidiano são mediações funda- 
mentais do processo histórico. Segundo Heller (2004), é nele que as pessoas vivem e a história se objetiva. Ele é vivido de forma mecânica, espontânea, repetitiva e areflexiva, mas é nele que há a possibilidade de superação dessa alienação, sendo que uma das formas de perturbá-lo e de suspender as pessoas da mesmice é a arte.

Vigotski (1999, p 308) corrobora tal concepção, afirmando que a arte nos faz deparar com elementos que "em nosso psiquismo não encontram vazão na vida cotidiana [...]" e se revelam explodindo nesse contato com a arte, despertando para a vida potencialidades imensas. E mais: ela "é uma espécie de sentimento social prolongado. E é nessa perspectiva que o texto busca analisar a potência de duas intervenções artísticas tradicionais para fomentar modos de (con)viver em um bairro, próximos à ideia espinosana de "comum"(ESPINOSA, Cap 2. §15) e de comunidade de Sawaia (2009); buscando, nessa análise possível fonte de inspiração para a práxis psicossocial.

O campo empírico da pesquisa foi o Morro do Querosene, situado na maior e mais populosa cidade do Brasil (zona oeste de São Paulo, bairro do Butantã), onde acontecem diferentes manifestações artísticas, tradicionais e contemporâneas, na forma de dança, canto e pintura.

\section{Percursos metodológicos}

A observação participante foi o procedimento adotado pela pesquisadora para facilitar o deflagrar dos dados, pois ela possibilita que a pesquisa se realize como um processo vivencial, proporcionando o "sentir com" ou como fala Vigotski (1999) a co-emoção, fundamental às pesquisas que trabalham com afetos. Essa convivência ocorreu durante dois anos, com visitas, passeios, muita conversa e participação nas festas do Morro registradas em diário de campo.

A entrada da pesquisadora no Morro se deu, inicialmente, pelo interesse na cultura maranhense do bumba meu boi, assistindo e participando do ciclo de festas que ocorre anualmente no bairro, que são o nascimento, batismo e morte do boi. O envolvimento com essas atividades permitiu conhecer mais de perto as pessoas e as relações que caracterizavam o bairro, bem como de todas as outras atividades artísticas ali desenvolvidas como a Orquestra de berimbaus, a Festa de Cosme e Damião e o projeto "Muros do Querosene", que embeleza com pinturas (naif e grafite) deixadas nos muros e calçadas do Morro. A pesquisadora participou dessas atividades durante dois anos de intensa convivência com o Morro e com algumas pessoas e artistas que foram se abrindo para conversas. Participou também das Reuniões da Associação Cultural dos Moradores do Morro do Querosene, a convite de uma das mora- 
doras do local, o que possibilitou conhecer mais diretamente as ações políticas ali viabilizadas.

Para compor o corpus da pesquisa foram escolhidas as duas manifestações artísticas mais tradicionais e que dão muita visibilidade ao local: a maranhense (bumba meu boi) e a baiana (capoeira), que são difundidas por dois grandes mestres que residem no local: Tião Carvalho e Dinho Nascimento, respectivamente. Em torno delas, foram registradas as suas festas e as afetações da plateia e foram entrevistados os dois mestres Também foram realizadas entrevistas com moradores locais, escolhidos conforme a pesquisadora foi se aproximando e conhecendo as pessoas que tinham interesse em participar de conversa sobre o viver no Morro. Ao todo foram 08 entrevistados com tempo de moradia, idade e gênero variados.

As entrevistas visaram complementar os diálogos registrados nos diários de campo e focavam especialmente as festas, o cotidiano do bairro, relações de vizinhança e as atividades diretamente políticas.

\section{A vida e a festa no Morro}

O Morro do Querosene tem uma história de luta e ações coletivas recheada de elementos artísticos, festivos e com destaque a cultura popular.

Essa história começa na década de 50, no início de seu processo de urbanização. Nessa época, não havia instalação elétrica no local e a iluminação das casas e das ruas durante a noite era feita por lampiões, daí o nome pelo qual o bairro é conhecido. Conforme relatos de alguns moradores mais antigos, essa característica também contribuiu para que as pessoas se voltassem para as ruas durante a noite para bater papo, fazer fogueira e cantar. Esse início já favorece o delineamento de um espaço no qual as pessoas saem de suas casas para se encontrarem nas ruas.

O "Morro", como é comumente chamado no cotidiano, também apresentava em sua origem algumas manifestações culturais como "São João comunitário", feijoadas e sambas nas casas dos moradores, como segue:

Mas aqui no Morro já tinha uma coisa interessante. Aqui já tinha pessoas que faziam, não festa como a gente, mas uma cantoria. Na casa da dona Adélia, ela fazia uma feijoada na casa dela, levava os cantadores, ficava ouvindo daqui a viola. Já teve, há muitos anos na rua, o pessoal fazia uma festa de São João. Uma coisa mais na rua, comunitária, não tinha nada a ver como se fosse a festa do boi. E a gente sabia que existia isso, mais acanhado, mas fazia. Lá em cima também no Mauro já fazia uma brincadeira. Quer dizer, são coisas acanhadas, mas que 
acontecia. Na casa da dona Adélia, ela já chamava os músicos pra tocar, fazia um feijoada. (Mestre Dinho Nascimento)

Essa veia festiva perdurou no tempo e, atualmente, o Morro é o cenário no qual grandes trabalhos envolvendo atividades artísticas tradicionais acontecem e são o foco deste estudo, como já mencionado: O Grupo Cupuaçu de Danças Brasileiras, que realiza as três grandes festas anuais do bumba meu boi maranhense, e a Orquestra de berimbaus.

Tião Carvalho é o mestre e um dos fundadores do Grupo Cupuaçu que teve início com sua chegada a São Paulo (na década de 80). É esse Grupo que promove o calendário festivo anual do bumba meu boi que cumpre o cronograma que completa o seu ciclo: o nascimento, que acontece no mês de abril; o batismo no mês de junho, e a morte do boi, durante o mês de novembro, todas acontecem aos finais de semana, elas têm início pela manhã, estendendo-se pelo restante do dia e se encerrando à noite. Essas festas contemplam, para além das manifestações do bumba meu boi, trabalhos de outros artistas do bairro e coletivos convidados de fora que realizam participações durante a programação; inclusive a orquestra de berimbaus se apresenta em todas essas festas.

A realização dessas festas envolve uma grande quantidade de pessoas de dentro e de fora da comunidade (cerca de mil pessoas frequentam cada uma delas, movimentando intensamente o lugar) a entrada é gratuita e muitas pessoas são frequentadoras assíduas, incluindo-se entre elas, homens, mulheres, idosos e crianças.

A orquestra de berimbaus tem como idealizador e promotor o mestre Dinho Nascimento. Dinho vem de Salvador (BA) e chega no morro por volta da década de 80, dando início a um movimento de ensinar as crianças durante as tardes de domingo a jogar capoeira e tocar berimbau na praça do centro do bairro. Com a ampliação do movimento nasce ali a orquestra de berimbaus, que atualmente é composta por jovens do bairro que ensaiam na casa do mestre, fazendo apresentações pela cidade de São Paulo em espaços culturais, além de também participar de parte da programação nas festas do boi realizadas pelo Grupo Cupuaçu. Destaca-se, ademais, que a relação do berimbau com o jogo da capoeira é essencial, pois o berimbau é o instrumento que conduz todo o jogo durante as rodas, definindo o seu início e seu fim, seu ritmo, velocidade, intensidade, etc.

Para além das iniciativas culturais, o Morro também é alvo de ações políticas que acontecem principalmente por meio da Associação Cultural dos Moradores do Morro do Querosene, que tem sua sede na casa de mestre Dinho Nascimento. Atualmente, uma das pautas mais urgentes da Associação é a luta 
pela construção do Parque da Fonte. Trata-se, em termos gerais, de um terreno de disputa entre os moradores locais e grandes empreiteiras. Há mais de dez anos, os moradores lutam para que numa área verde de aproximadamente $40.000 \mathrm{~m}^{2}$ seja construído, com a ajuda do poder público, um parque que contemple a história indígena do local, e promova a preservação ambiental do terreno que contempla cinco nascentes de água. Por outro lado, está a força do capital, que vê no terreno uma possibilidade imperdível de construção de algum empreendimento imobiliário lucrativo, sem levar em consideração as peculiaridades da vegetação, da história local, da cultura etc.

A multiplicidade de iniciativas que envolvem a arte, a política, movimenta o bairro todo e seus moradores, principalmente por ocasião das festas que são realizadas por esses dois grandes movimentos regularmente.

Esse conjunto de qualidades relacionais e atividades mostra indícios de uma comunidade que emerge, mas para tal afirmação ter validade é necessária a apresentação do que significa esse conceito, no presente texto. Seguindo as orientações de Sawaia (2009), uma das qualidades da comunidade é a de que ela supera dicotomias clássicas como:

\begin{abstract}
coletividade e individualidade, ser humano genérico e ser humano particular, apresentando-se como espaço privilegiado da passagem da universalidade ética à singularidade do gozo individual. Um movimento de recriação permanente da existência coletiva, fluir de experiências sociais vividas como realidade do eu e partilhadas intersubjetivamente, capaz de subsidiar formas coletivas de luta pela libertação de cada um e pela igualdade de todos. (SAWAIA, 2009, p. 48)
\end{abstract}

Não se trata de defini-la ou de cristalizá-la em uma identidade territorial. Comunidade não é um estado, um conjunto de atributos que definem um espaço. Cristalizar uma identidade de comunidade é torná-la um sistema de controle, autorizando pessoas a falarem em nome dela e a definirem os que devem ser dela excluídos. "Comunidade é uma inteligência coletiva voltada à descoberta de novas formas de viver" (PARKER, 2015, p. 233), um sentimento da utilidade da cooperação e da concórdia para o fortalecimento da potência de vida de cada um. Na direção das ideias de Espinosa, define-se que:

A conjugação das potências individuais exprime-se num direito comum, ou seja, no ordenamento jurídico através do qual a "comunidade" assim constituída determina a potência de cada um, ou seja, aquilo que ele pode, ou não, dizer e fazer. Na verdade, cada indivíduo, podendo embora pelo direito natural dizer, fazer e possuir tudo o que quiser, "não tem realmente sobre a na- 
tureza nenhum direito para além daquele que o direito comum lhe concede" (SPINOZA, 2009 p. XXIII).

Espinosa nos ensina que Comunidade é questão ontológica (inerente à condição humana). Viver em comum é necessidade fundamental do ser humano, como o são a comida, o sono e a saúde e, por conseguinte um direito natural, que vai além dos resultados úteis previstos em seu desenvolvimento. A ética espinosana mostra que "nada é mais útil ao homem que o outro homem" (E IV, prop. 35, corol. I) e que é esse desejo do útil comum que está na base da criação da sociedade. Essa concepção inverte a forma clássica como comunidade é trabalhada pela psicologia. Não se trata de compreender porque um grupo não é comunidade e potencializá-lo para tanto, mas de compreender quais os bloqueios que impedem que o sentimento do comum possa nascer e permanecer.

Assim, entende-se que comunidade se refere mais a propriedades e princípios que se configuram objetivamente de forma dinâmica e instável do que a um conceito pronto e acabado. Ela pode ser entendida como um lugar de intervenção psicossocial, pois rompe com a cisão entre espaço público e espaço privado e é onde o coletivo se encontra na construção do comum, sem diluir as singularidades bem como de ideia ético política reguladora da intervenção territorial. Ela se contrapõe a praticas individualistas e adaptativas, elegendo como objeto o coletivo e como objetivo a sua configuração como um sujeito político constituído por sujeitos singulares e potentes à ação coletiva.

Acrescenta-se ainda que cada comunidade é uma singularidade, com ritmo, desenho e relações especificas, que carrega uma ou mais necessidades que precisam ser conhecidas e respeitadas, sem que isso elimine o que há de essencial, que segundo Espinosa é o sentimento do comum que abre a possibilidade da alegria gerada pela potência de agir coletivamente, de finalmente ser forte, por formar um todo poderoso.

Com este olhar procedeu-se a análise dos registros realizados durante os dois anos de convivência no Morro do Querosene sobre a experiência de viver no Morro e junto com as atividades artísticas ali realizadas. Deste modo, três unidades de análise emergiram como centrais e aglutinadoras da diversidade dos sentidos dos moradores e mestres do lugar. São elas: Ações políticas, sentimento e território. Estas unidades contribuíram para nortear a discussão referente à relação entre as qualidades comunitárias do bairro e as afetações nele provocadas por manifestações de cultura popular. Antecipando as considerações finais, afirmamos que as análises indicam que comunidade é mais que espaço geográfico, é uma força, uma potência política coletiva, permeada por um sentimento de comunidade, conforme exposto a seguir. 
No que tange às ações políticas, foi destacado o embate entre os moradores locais e os interesses capitalistas de especulação imobiliária em torno do terreno da Chácara da Fonte. Vale informar que a disputa por esse terreno é potencializada pela Associação Cultural do Morro do Querosene, que existe desde o ano de 1998, e viabiliza ações políticas com diferentes pautas no bairro, sendo que, atualmente, a luta tem sido pela construção do Parque, conforme já descrito.

A unidade denominada de sentimento mostra que comunidade não se restringe a um espaço físico, mas contém uma força, uma potência coletiva e comum entre as pessoas que a habitam. A análise dos afetos expressos nas narrativas demonstra diferentes afetações entre os moradores e os participantes de fora. Moradores e não moradores destacam as afetações emocionais individuais, tanto na direção do sentido catártico proposto por Vigotski (1999) como no seu sentido oposto, de harmonização das emoções. O trecho do diário de campo de uma das festas presenciadas elenca uma série de sensações experimentadas na parte final da morte do boi:

Já estava de noite, era a hora de o boi ser laçado e morrer. Foi
um momento tenso, triste e extremamente bonito. Os integran-
tes do grupo se emocionam muito nessa hora, a morte do boi
simboliza uma série de pequenas mortes que acontecem ao lon-
go do ciclo que se encerra. Agora, os versos dizem em tom lento
e calmo: "SO meu boi já morreu, ficou triste o meu terreiro, mas
no ano que vem eu canto boi o ano inteiro.J. " Muitas pessoas
choraram, se abraçaram, beberam a sangria1 do boi preparada
por uma das integrantes mais antigas do Grupo Cupuaçu. Após
o encerramento do ritual, encontrei D'Olinda, artista local, bas-
tante emocionado, ele dizia que "a festa é cada vez mais forte,
mais linda, e que é muita energia pulsante". (Diário de campo)

O sentimento expresso por D'Olinda nos revela uma explosão emocional comum, que proporciona uma experiência do comum, o sentir com, partilhar emoções. Ainda, entre os moradores aparecem referenciais ao que podemos categorizar como um sentimento de comunidade, isto é uma emoção com continuidade no tempo que se reverte em mudanças nas relações:

essas pessoas se encontram muito nas casas, nos bares, padaria,
não sei o quê, as pessoas saem das suas casas. Você conhece as
pessoas da sua rua. Você vai, vê uma comunidade. Se você for
no Bixiga, por exemplo, ali do lado da Vai Vai, é capaz de você
encontrar uma semelhança, entendeu? E eu não sei se você vai
encontrar essa semelhança na Paulista com a Augusta, né. Essa

$1 \quad$ O sangue do boi é preparado por uma das anfitriãs da festa e fundadora do Grupo Cupuaçu: Graça Reis faz a sangria com vinho e a distribui a todos os participantes em uma bacia de prata. O vinho é distribuído e consumido por todos que estão ali presentes, num ritual denso e bonito. Às crianças, a bebida é produzida com suco de uva. 
comunidade onde as pessoas se encontram aqui, é o futebol ali, os filhos estudam geralmente boa parte na mesma escola e cresce junto ali e tal, jogam bola e tal e aí cresce, dando hora. Acho que tem um espírito de comunidade, comunidade pra mim é isso. (Depoimento de Tião, grifo nosso)

Como explícito neste relato, o sentimento de comunidade está muito associado com a prática cotidiana das pessoas de saírem de suas casas, andarem na rua, e de se conhecerem. E esses encontros são, em grande parte, favorecidos pela geografia mesma do lugar, pelo desenho de seu território, pela topografia do Morro, que foi a nossa terceira unidade de análise. Todas as ruas do bairro, por exemplo, se encontram numa rotatória, que é conhecida como a "pracinha" do lugar e que, além de ser um ponto de encontro, é também onde ocorre a maioria das manifestações culturais locais. Além do mais, o bairro fica situado no ponto mais alto do Butantã, no entroncamento de importantes rodovias e avenidas como: Raposo Tavares, Imigrantes, e a Avenida Corifeu de Azevedo Marques onde se situa a cidade universitária da Universidade de São Paulo (USP). Outro elemento associado ao território e que favorece essa ida às ruas é o fato de que no bairro não há uma grande movimentação de carros, e os ônibus não circulam por ali, porque é inviável subir suas estreitas ladeiras. Então existe uma certa liberdade, inclusive para que as festas aconteçam nas ruas, e uma segurança em relação ao sair de casa, ficar na calçada, brincar na rua, etc. Tais características objetivas do território permitiram que a vida do Morro se distanciasse da organização social e política capitalista que orienta a urbanização da cidade de São Paulo. Tião afirma que foi morar no bairro inicialmente por uma questão muito pontual que se referia ao valor do aluguel naquela época (década de 80). Assim, ele aponta mais uma influência da característica topológica do terreno, a de interferir no seu valor de mercadoria, o que pode ter influenciado no perfil dos seus moradores. Em decorrência da precária infraestrutura inicial do bairro, os imóveis não eram tão valorizados como são hoje em dia, atraindo muitos artistas e estudantes, que, ao se instalarem no local, colaboraram em fazer dele espaço alternativo de se viver na cidade de São Paulo e de conviver com manifestações de cultura popular. E ambos os mestres foram ficando por terem tido a sensibilidade de enxergar no lugar uma informalidade nas relações, proporcionada em grande parte pela qualidade de seu aspecto geográfico e mercadológico:

E o espaço do Morro, a gente sente que é um espaço propício geograficamente, certo. Geograficamente ele é um espaço propício e a gente descobriu isso, que era um espaço propício pra fazer cortejo na rua, foi uma forma que a gente conseguiu também conquistar essa comunidade né. Chamava, "quer ir lá 
pra casa", chamava em dia de festa, um ou outro, parente, então foi virando uma coisa nossa né. (Mestre Tião)

Mestre Tião explana com sensibilidade a intricada relação entre geografia física e geografia humana, entre fatores econômicos, geográficos e psicossociais, bem como a mediação da arte nessas relações.

Uma vez constatados os sentidos dos afetos no Morro, é o momento de ampliar a reflexão sobre arte e transformação na forma de (con)vivência em um território, objetivo da pesquisa realizada.

\section{Percursos teóricos}

A concepção de arte adotada é fruto de duas teorias, uma sociológica que resgata autores que contribuem para pensá-la enquanto um fenômeno social e uma análise psicossocial que tem por base a concepção de arte do autor central da psicologia sócio histórica, Vigotski (1999), que defende a arte como "técnica social das emoções", a linguagem das "emoções inteligentes".

A análise sociológica destaca a expressão "cultura popular", termo utilizado pela literatura levantada (CANCLINI, 1983; CERTEAU 1995; CHAUÍ, 1986) entendendo-a como produto histórico, atravessado por contradições sociais; e que responde a elas de diferentes formas e nuances/ entre o resistir e o sucumbir à ordem hegemônica do modo de produção capitalista. Importa deixar claro, além do mais, que a literatura consultada na análise sociológica utiliza o termo "cultura popular" em contraposição à cultura dominante e não à erudita.

Tal concepção é importante para que não se cometam erros clássicos como os de considerá-la apartir de perspectivas reducionistas, tanto da perspectiva do Romantismo como de seu oposto a Ilustração. A tradição romântica concebeu o popular como o modelo de vida ideal, no qual o povo é entendido como uma totalidade homogênea, ingênua e ainda sem força política. E na visão ilustrada/positivista, as culturas populares são observadas de fora, como elemento exótico, desconsiderando-se as suas contradições, seus conformismos e resistências e seu caráter transformador. Os ilustrados "estão contra a tirania, em nome da vontade popular, e contra o povo, em nome da razão" (CHAUÍ, 1986, p. 17). Assim,

podemos pensar a cultura popular como processos complexos que contemplam contradições que convivem como resistência, potência, hegemonia e contra-hegemônica. O fato essencial é que ela não existe passivamente, mas abala as estruturas, os modos de ser e estar no cotidiano, está em tensão com a cultu- 
ra dominante, mas muitas vezes também se conforma com ela.

(SANTOS, 2015, p. 29)

Essas análises sobre cultura popular orientam a não cair na compreensão ingênua e romântica de manifestações artísticas tradicionais, mas de situá-las no período histórico em que acontecem, no presente caso mostrando a tensão entre a influência massiva do mercado e o esforço dos artistas/mestres na contraditória realidade de manter uma tradição que se transforma. Nossa pesquisa demonstra o esforço dos mestres em transgredir, resistir ao modelo mercadológico dominante, mantendo uma arte que é diferente do que é vendido nos meios de comunicação de massa; fazer da tradição uma força de transformação.

As expressões de arte mais praticadas no Morro do Querosene, como já visto, são o bumba meu boi e a capoeira, ambas são tradicionais e apresentam, na sua forma e conteúdo, a tensão entre dominação e resistência. $O$ auto que é encenado nas "festas do boi" conta a história de um casal de ex-escravos (Pai Francisco e Catirina) que desafia o poder do amo ao matar o boi dançarino da fazenda para satisfazer o desejo da mulher que estava grávida. Porém, ao mesmo tempo em que enfrenta o poder por capricho da esposa, Pai Francisco tenta, a todo custo (e consegue) trazer de volta a vida ao boi mais precioso de seu patrão; no intuito tanto de se redimir da infração cometida como também de dar continuidade à festa que girava em torno do animal.

A capoeira, por sua vez, possui uma história de luta e resistência. Os negros escravizados utilizavam-na, inclusive, como um instrumento para lhes auxiliar na luta pela sua liberdade.

\footnotetext{
Pode ser até que o nome da luta venha justamente disso. Negro fugia era para o mato. Se algum capitão-do-mato o alcançava, se era um a um, numa clareira, numa capoeira - então, ali, o negro era mais livre para se defender. E dizem também que esse jeito de lutar de brincadeira como ainda fazemos hoje, era a maneira do escravo se exercitar, disfarçando de bailarino na frente do feitor. Acho que é até verdade, capoeirista é mesmo muito disfarçado, ladino e malicioso. Contra a força, só isso mesmo. Está certo. (PASTINHA, 1967, p. 5)
}

Ela se configura em um contexto sócio-político importante da sociedade brasileira, pois os negros se utilizavam da Capoeira como forma de enfrentamento da perseguição dos feitores, criando uma resistência física que era praticada de modo disfarçado, através de uma brincadeira, dança e luta. De acordo com Abib (2004), a capoeira surge, tanto enquanto um elemento agregador das diferentes etnias africanas interagindo na colônia, como também enquanto 
um instrumento ardiloso de luta contra "a situação de extrema violência a qual estavam os negros escravos submetidos, e no qual o saber corporal inscrito em cada perna, braço, tronco, cabeça e pé, podia ser transformado numa arma eficaz a serviço da sua libertação" (ABIB, 2004, p. 96).

Não obstante, assim que se descobriu a luta que era praticada por eles, ela foi violentamente proibida. "Um negro que agredisse um feitor ou que fosse pego treinando era ferozmente torturado, muitas vezes até a morte, para que servisse de exemplo e desencorajasse os outros escravos a praticá-la" (FREIRE, 1986, p. 243).

É nessa relação de conformismo e resistência (CHAUÍ, 1986) que a cultura popular é praticada no cenário histórico da sociedade brasileira, mas sempre em clima de festa e beleza.

No Morro do Querosene, o bumba meu boi e a orquestra de berimbaus atuam há mais de trinta anos, marcando e sendo marcados pelo seu território. Ambos os movimentos conversam com a sociedade e seus instrumentos de dominação através de uma dança e uma música que afetam a sociabilidade e a materialidade do bairro, plantando embriões de um sentimento de comum na dialética entre o singular e o social no processo.

Vigotski nos ajuda a entender essa dialética, especialmente quando afirma que:

\begin{abstract}
A arte é o social em nós, e, se o seu efeito se processa em um indivíduo isolado, isto não significa, de maneira nenhuma, que as suas raízes e essência sejam individuais. É muito ingênuo interpretar o social como coletivo, como existência de uma multiplicidade de pessoas. O social existe até onde há apenas um homem e as suas emoções pessoais. Por isto, quando a arte realiza a catarse e arrasta para esse fogo purificador as comoções mais íntimas e mais vitalmente importantes de uma alma individual, o seu efeito é um efeito social. (VIGOTSKI, 1999, p. 315)
\end{abstract}

Ao afirmar que ela é "uma ferramenta social das emoções", o autor indica que não se trata de processo individualista, nem psíquico e privado. Nem poderia, pois segundo o autor, os afetos têm sua gênese fora do psiquismo, portanto, embora sejam vividos como sentimento do eu, eles são sócio-históricos. Uma das importantes contribuições de Vigotski à psicologia é sua concepção de emoção e por isso a necessidade de se remeter aos seus estudos na análise de manifestações culturais. Uma vez que ele recupera a positividade das emoções na psicologia, tirando-as do lugar do erro e do psicologismo, e apresentando-as como espaço de vivência da ética, pois qualificam as ações e relações humanas (SAWAIA, 2006). Ele buscou na teoria das emoções de Espinosa (Ética), 
orientações para trabalhar a dimensão ético-política das mesmas. Este filósofo defende que razão e emoção e corpo e mente são inseparáveis. E que os afetos são a porta de entrada do conhecimento do mundo e essa experiência envolve a afetação do corpo e da mente conjuntamente, uma vez que para Espinosa,

\begin{abstract}
$\mathrm{O}$ que quer que aconteça no objeto da ideia que constitui a mente humana deve ser percebido pela mente humana, ou seja, dessa coisa dar-se-á necessariamente na mente a ideia; isto é, se o objeto da ideia que constitui a mente humana for um corpo, nada poderá acontecer nesse corpo que não seja percebido pela mente. (ESPINOSA, E II, P12)
\end{abstract}

Vigotski inseriu essas ideias na psicologia marxista para explicar também a emergência do singular e da criação apesar da determinação social, abrindo o diálogo entre psicologia e arte. Diálogo que inicialmente foi motivado pelo seu interesse como crítico e apreciador de arte de ampliar seus conhecimentos sobre estética. Segundo ele, o que define arte é a sua recepção, questionando as explicações simplistas, quer sociológicas (que buscam explicações na sociedade), psicanalistas (que a relaciona às qualidades psicológicas do artista) ou formalistas (que reduzem o debate à forma da obra de arte). E essa recepção deve ter a potência de transformação social e individual. Para analisar tal processo ele destaca o conceito de catarse em sentido oposto ao de Aristóteles, que a definia como um processo de purificação e limpeza da alma.

Para Vigotski, catarse é um momento do curto circuito das emoções, da explosão entre emoções contrárias que a arte provoca.

\begin{abstract}
A verdadeira natureza da arte sempre implica algo que transforma, que supera o sentimento comum, e aquele mesmo medo, aquela mesma dor, aquela mesma inquietação, quando suscitadas pela arte, implicam o algo a mais acima daquilo que nelas está contido. (VIGOTSKI, 1999, p. 307)
\end{abstract}

Nessa frase ele destaca que a arte incita sensações que nos levam para além das experiências ordinárias e despertam no corpo e na alma sentimentos que caminham em sentidos opostos e contraditórios, culminando no que o autor identificou como uma contradição emocional, o "verdadeiro efeito da obra de arte" (VIGOTSKI, 1999, p. 269): uma catarse. Esse conceito é central para a compreensão das análises de Vigotski a respeito da arte e de sua relação com os afetos e a transformação social.

Como já dito, para ele, a catarse, por despertar sentimentos opostos, leva o indivíduo a experimentar o novo, e a entrar em contato com emoções anteriormente represadas e que vêm à tona por meio da arte. 
São essas concepções que estão por traz de três importantes afirmações de Vigotski (1999) sobre arte, que sintetizam sua teoria: "a arte é "o social em nós" (...), "a arte é "técnica social das emoções" e ao mesmo tempo a arte é a linguagem das "emoções inteligentes".

A primeira afirmação (o social em nós) remete ao caráter universal da arte que propicia a experiência do comum, pois a obra de arte não reflete a emoção particular do artista, mas um sentimento universal que a sensibilidade do artista capta. A segunda (técnica social das emoções) destaca a capacidade de sentir com, de partilhar emoções, o que pode motivar ações coletivas dentro de territórios. A terceira (emoções inteligentes) refere-se à não separação entre razão e emoção, mas também à negação do espontaneísmo da atividade artística. Ela não é um adereço à vida, mas "a mais importante concentração de todos os processos biológicos e sociais do indivíduo na sociedade" (VIGOTSKI, 1999, p, 329) que se expressa na relação do ser humano com o mundo nos momentos mais intrincados da existência.

\section{O invisível indispensável}

Todas essas características da relação arte, cognição e afeto, analisadas por Vigotski, foram explicitadas nas observações e conversas partilhadas com os moradores e mestres. Como já afirmado, esses últimos destacam a arte como um sentimento social mobilizador do comum. Os mestres (Tião Carvalho e Dinho Nascimento) são as figuras centrais em torno das quais a arte é suscitada, vivida, e experimentada sempre no coletivo. Eles afirmam não conseguir fazer arte na solidão e que comum, portanto, é uma necessidade que se constitui e se expressa no coletivo, nas relações com a comunidade e no compromisso com o lugar.

\footnotetext{
E aí a gente tá aí com a referência do antigo, mas antes dele teve o outro, tanto na capoeira, no bumba-meu-boi. Então assim, dentro do morro a gente tem já essa diversidade. Pode não morar alguém aqui que faz um jongo, mas a gente tá sempre trazendo pessoas, e aí isso fortalece a cultura e fortalece o local. Então a minha contribuição dentro do local é essa. E a comunidade, até agora tá aceitando. (Mestre Dinho Nascimento)
}

O que mais foi ressaltado na pesquisa é que a potência ligada à arte e à cultura popular não se restringe ao mundo pessoal, mas rompe com a cisão entre o pessoal e o coletivo. Ficou claro que manifestações artístico-culturais e sentimento de comunidade constituem uma unidade inseparável no Morro, muito em decorrência das ações dos mestres que promovem as atividades no lugar. Os próprios mestres são motivados pelo sentimento do comum. Suas 
narrativas revelam que o artista da cultura popular se alimenta do comum, como fala Tião:

mas é isso, de estar com as pessoas, né. A partir do momento em que a pessoa se vincula, que ela vem participar, que ela começa se abrir pra conversar com a gente, isso já é um trabalho. A gente já tá fazendo um trabalho social, psicológico, cultural. Quando as pessoas procuram, vêm tirar suas dúvidas, geralmente elas vêm procurar esse líder pra conversar né. São essas pessoas que fazem essa liderança que geralmente são chamadas: Tião, ou Dinho. (Mestre Tião)

Essa motivação dos mestres nos leva a entendê-los como artistas do "invisível”, conforme definição teórica de Kaplan (2005). Os artistas do invisível conseguem enxergar dentro de um organismo social as potências coletivas por onde é possível atuar em conjunto de forma orgânica, trabalham com o social desenvolvendo sua intuição de modo a compreender o espaço como um potencial de mudanças, transformações e catarses necessárias. A sensibilidade é o centro de suas práticas, o que contribui para que vejam a totalidade do processo com o qual se envolvem, formando organismos sociais vivos com potência de transformação.

\begin{abstract}
Quando formamos organismos sociais, ao viver ou trabalhar neles, chamamos à vida forças vivas que estão além de nosso conhecimento individual ou controle; são habilitados novos mundos, novos seres, novas formas de vida, maiores do que nossos seres individuais, imprevisíveis e imensos. Nossos processos vivos são ativados e tornam-se manifestos. Novas totalidades são criadas, com seu próprio poder indelével. (KAPLAN, 2005, p. 52)
\end{abstract}

Além do mais, a presença do afeto é uma constante nesse movimento de ação coletiva dos mestres junto à comunidade, contribuindo para aumentar as potências de agir individuais e coletivas. Como sinaliza uma parte da resposta de Tião à pergunta se ele acha que a festa do boi consegue tocar no coração das pessoas?

T: Claro, como não? Você acha que as pessoas vêm aqui porque cada uma vai receber mil reais no final da festa? Vai ter um prêmio, não sei o quê? As pessoas vêm aqui porque elas gostam, porque gostam bastante, porque querem participar. (Depoimento de Tião)

Essa é a afetação mais destacada pelas pessoas que participam das festas, mas não são moradoras do Morro: o desejo de expansão da alegria, de ex- 
plosão e também de harmonização das emoções. Isto é, um espaço gratuito e privilegiado de afetação coletiva do corpo e da mente.

\section{As festas e os afetos}

Também podemos inferir dessas análises uma outra reflexão sobre arte tradicional versus novas formas de arte. A relação com a comunidade pode ser uma das explicações da permanência dessas manifestações artísticas tradicionais ao longo da história, enquanto força de afetação coletiva, rompendo temporalidades e não sendo eliminada pelas novas formas populares de arte, até entre os jovens. De outro lado, a pesquisa demonstra um cuidado a ser tomado com a preservação da tradição artística, para que ela não se cristalize. Pois embora as festas sejam públicas e abertas, algumas pessoas da comunidade se queixam de que a preocupação excessiva com a tradição acaba tolhendo as possibilidades de participação daqueles que não possuem habilidades musicais ou para realizar passos de dança com destreza. A escassez dos figurinos também é um motivo de queixa, principalmente nas atividades viabilizadas pelo grupo Cupuaçu que tem um cuidado primoroso com os fundamentos originais das expressões artísticas que recriam. A fala de Cecília, companheira de mestre Dinho Nascimento aponta para essa direção do rigor que pode tolher e limitar a experiência, por conta do preciosismo da tradição:

\footnotetext{
Então hoje eles conquistaram o espaço deles como maranhenses, fortes nesta tradição e acho que é isso. [...]. No começo quando eu começava a dançar tambor de crioula eu entrava, mas tentando ver como é que a coisa ia. E eu achava muito ruim porque "agora você entra, agora você sai, agora terminou, agora faz isso." Porque tem um transe né, tem um tempo. Porque depende, às vezes a pessoa fica um minuto e já quer sair, a outra pode querer ficar um pouco mais, é um respeito mútuo. Hoje você quis ficar cinco minutos, mas eu lhe respeito. É um jogo assim, não dá pra chegar pra você e falar "Não, agora você sai porque já deu o tempo e a outra vai entrar." Hoje em dia é difícil de eu entrar num tambor de crioula.
}

Outra inferência importante é sobre o local das apresentações artísticas. Por acontecerem na rua, elas favorecem os encontros e a participação democrática. Para participar de uma manifestação popular realizada na rua, não precisa muita coisa, basta estar perto, estar aberto, ter um corpo e uma alma para sentir as explosões de energia nervosa que são expressas na sua forma e no seu conteúdo.

Vigotski destaca ainda as duas dimensões fundamentais da arte: forma e conteúdo e que a contradição entre elas é fundamento da força catártica da 
arte. Como já sinalizado, para Vigotski, o que define uma obra de arte é a recepção, sendo a catarse a expressão suprema dessa afetação.

O conteúdo do bumba meu boi por exemplo, nas festas de sua morte, é triste e crítico. No entanto, os trajes são coloridos, a dança e a música são vibrantes e bonitas simbolizando uma alegria densa. A observação participante permitiu a constatação de que adultos e crianças choram copiosamente ao se depararem com a morte do boi e algumas pessoas, como Juliana, afirmam: "eu vou embora, mas a festa fica no meu corpo" demonstrando uma afetação que se aproxima muito do que Vigotski $(1999$, p. 83) denomina como a sensação catártica, onde:

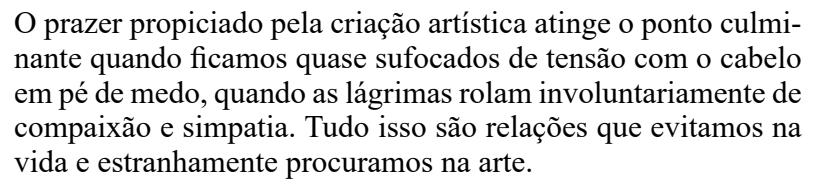

Por outro lado, como o próprio Vigotski afirma, a reflexão psicossocial tem que ter uma teoria social, não se pode deixar de apontar que, a despeito da potência de afetação coletiva e de mobilização, as manifestações artísticas ocorrem em uma sociedade e, portanto, são atravessadas pelos conflitos que a caracteriza e pelo sentido dominante de mercantilização das coisas e pessoas e do individualismo. Daí também sua capacidade de atração. Elas trazem a possibilidade de resistir à solidão/individualismo e à mesmice emocional e de se afetar por emoções jamais sentidas pelo corpo e pela mente no decorrer ordinário da vida.

Em síntese, não se pode afirmar categoricamente que as festas populares no Morro do Querosene irão sempre promover potência de resistência aos dispositivos de exploração do mercado imobiliário, (como no caso citado da Chácara da Fonte) e de alienação dos corpos e mentes que caracterizam uma sociedade marcada pela desigualdade social.

Mas é preciso destacar que a pesquisa revela que o Morro está aceso e está em festa, muito em decorrência da presença das diferentes expressões populares que habitam esse lugar. As festas carregam um grau de imprevisibilidade no sentido de suas afetações.

No entanto, fica ressaltada a permanente possibilidade de experimentar o sentimento de comum, novas formas de (con)viver", pela via do dissenso, no sentido mais exímio do termo: "uma perturbação no sensível, uma modificação singular do que é visível, dizível, contável” (RANCIERE, 1996, p. 372).

Os mestres são movidos pelo desejo do comum, essencial para a realização de suas atividades artísticas. E, o que é também importante, eles demonstram 
sensibilidade para escolher manifestações artísticas tradicionais que contem com mais evidência algo de virulento, a contradição, mesmo em personagens delicados como o de Catirina, esposa de Pai Francisco.

Em síntese, eles sugerem, por meio de suas atividades e das entrevistas realizadas, que é possível fazer a vida por outras vias, a partir da potência de agir emergente nas atividades com cultura popular, pelas vias que resistem ao individualismo e à solidão. Ambos chegam à São Paulo no intuito de viver de sua arte, de trazer outra referência do Nordeste para a capital, como afirma Tião: esse grupo de maranhenses vem com essa intenção: de nos colocarmos de outra forma em São Paulo; de se valorizar, de trazer outra ideia. Ademais, Dinho Nascimento ressalta também a sua meta ao chegar na cidade na década de 80, que era "viver de arte, de cultura":

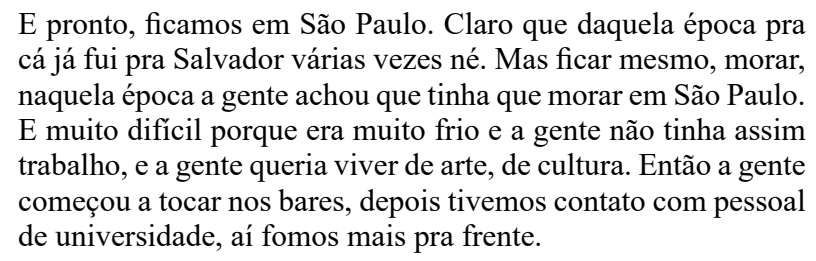

Não é caminho fácil ou romântico, como apregoa o estereótipo dominante de artista. Ele é ambíguo, pois, se por um lado é o lugar da alegria (alegria inteligente e não alienante) e de muito trabalho, é também o lugar da exploração, da necessidade de sobrevivência, conflitos que a arte não escamoteia, mas fortalece.

Por isso mesmo, esses "artistas do invisível" talvez possam servir de inspiração à práxis psicossocial que não desiste de buscar, na história, brechas à potência das forças vivas do comum, compreendendo (comum)idade como sinônimo de bons encontros, aqueles que, segundo Espinosa, aumentam a nossa potência de agir. Para esses mestres, viver em comum é necessidade fundamental ou ainda, um direito natural (comum a todos os corpos), mas que, na concepção espinosana, deve ser garantido pelo direito civil, fundante da vida comum e que tem como mote prolongar o direito natural. "O direito de ser parte de um todo", em que as partes coexistem porque possuem desejos comuns e percebem a utilidade das outras para sua própria conservação e expansão da sua liberdade e felicidade. "Acrescentamos que sem mútua cooperação os homens nunca poderão viver bem e cultivar a sua alma" (ESPINOSA, Cap.1, §15).

O desejo do comum, expresso pelos dois mestres como fundamental ao exercício das manifestações artísticas com as quais trabalham, lhes dá sensibi- 
lidade para escolher territórios favorecedores de bons encontros. Mas é claro, e eles sabem disso muito bem, que a escolha depende do valor mercadoria/ espaço urbano e da renda necessária à sobrevivência de si e da família ou dos que deles dependem.

E é nessa relação entre direitos naturais e sociais e entre forças transgressoras e reguladoras que eles vão redescobrindo novos modos de sentir, pensar e agir no desenho urbano, buscando unir múltiplos e diferentes corpos e mentes espalhados, colaborando, assim, para superar aquilo que Espinosa definiu como solidão: " aquela cidade cuja paz depende da inércia dos súditos, os quais são conduzidos como ovelhas, para que aprendam só a servir, mais corretamente se pode dizer uma solidão do que uma cidade" (SPINOZA, TP, Cap. V, §4).

\section{Referências}

CANCLINI, N. G. As culturas populares no capitalismo. Tradução Cláudio Coelho. São Paulo: Brasiliense, 1983.

CERTEAU, M. A cultura do plural. Campinas, SP: Papirus, 1995. (Coleção Travessia do Século).

CHAUÍ, M. Conformismo e resistência: aspectos da cultura popular no Brasil. São Paulo: Brasiliense, 1986.

ESPINOSA, B. Ética. Tradução Tomaz Tadeu da Silva. Belo Horizonte: Autêntica, 2008..

SPINOZA, B. Tratado político. Tradução, introdução e notas: Diogo Pires Aurélio. São Paulo: Martins Fontes, 2009.

FREIRE, R. Viva eu, viva tu, viva o rabo do tatu. 6. ed. São Paulo: Global, 1986.

HELlER, A. O cotidiano e a história. Tradução Carlos Nelson Coutinho e Leandro Konder. São Paulo: Paz e Terra, 2004.

KAPLAN, A. Artistas do Invisível: O processo social e o profissional de desenvolvimento. (Série Tornamento); Tradução Ana Paula Pacheco Chaves Giorgi. São Paulo: Instituto Fonte para o Desenvolvimento Social; Editora Fundação Petrópolis, RJ, 2005.

OLIVEIRA, B. A dialética do singular-particular-universal. In: ABRANTES, A. A.; SILVA, N. R. da; MARTINS, S. T. F. (Orgs.). Método Histórico-Social na Psicologia Social - Petrópoles, RJ: Vozes, 2005, p. 25-51.

PARKER, I. Revolução na psicologia. Campinas, SP: Alínea, 2014

PASTINHA, V. F. É luta, é dança, é capoeira. Revista Realidade, n?, p. ?-?. Fev. 1967. Disponível em: http://velhosmestres.com/br/pastinha-1967. Acesso em 11 nov., 2016. 
RANCIERE, J. O dissenso. In: NOVAES, A. (Org.). A crise da razão. São Paulo: Companhia das Letras; Brasília, DF: Ministério da Cultura; Rio de Janeiro: Fundação Nacional de Arte, 1996, p. 367-382.

SANTOS, L. M. Dos encontros com cultura popular no Morro do Querosene: um estudo do movimento bairro/comunidade. 2015. - Dissertação (Mestrado em Psicologia Social). Pontifícia Universidade Católica de São Paulo, São Paulo. 2015.

SAWAIA, B.B. Comunidade: a apropriação científica de um conceito tão antigo quanto a humanidade. In: CAMPOS, R. H. F. (Org.). Psicologia Social Comunitária: da solidariedade à autonomia. 15. ed. Petrópolis, RJ: Vozes, 2009, p. 35-53.

Comunidade: a apropriação científica de um conceito tão antigo quanto a humanidade. In: CAMPOS, R. H. F. (Org.). Psicologia Social Comunitária: da solidariedade à autonomia. 15. ed. Petrópolis, RJ: Vozes, 2009, p. 35-53.

VIGOTSKI, L. S. Psicologia da arte. Tradução de Paulo Bezerra. São Paulo Martins Fontes, 1999.

1999.

Psicologia da arte. Tradução de Paulo Bezerra. São Paulo Martins Fontes,

Agradecimento: CNPq (Conselho Nacional de Desenvolvimento Científico e Tecnológico).

Submissão: $17 / 08 / 2016$

Revisão: 01/11/2016

Aceite: 16/11/2016

Livia Maria Camilo dos Santos é doutoranda em Psicologia Social no Programa de Estudos Pós-Graduados em Psicologia Social da PUC-SP, e professora tutora no Ensino à Distância nas Faculdades Metropolitanas Unidas (FMU). E-mail: limac62@hotmail.com

Bader Burihan Sawaia é professora titular do Programa de Estudos Pós-graduados em Psicologia Social da PUC-SP. Coordenadora do GT/CNPq Afetividade e a dialética exclusão/inclusão, do NEXIN - Núcleo de pesquisas psicossociais da dialética exclusão/inclusão da PUCSP e membro do GT/ANPEPP A Psicologia Sócio-Histórica e o contexto brasileiro de desigualdade social.

E-mail: badbusaw@pucsp.br 